\title{
Negative Impact of Electronics Use on Lebanese Pediatric Population Aged between 2 and 6 Years
}

\author{
Sawsan Yaacoub, Amal Naous ${ }^{*}$, Mariam Rajab, Bassem Abou Merhi
}

MD, Pediatric Department, Makassed General Hospital, Beirut, Lebanon

DOI: $\underline{10.36347 / \text { sjmcr.2020.v08i02.001 }}$

| Received: 20.12.2019 | Accepted: 27.12.2019 | Published: 08.02.2020

*Corresponding author: Amal Naous

\section{Abstract}

Original Research Article

Background: Children tend to be active consumers of electronics and many electronic products are targeted to the youth market. Excessive use of such electronics prone children to aggressive behaviors, sleep disorders, impaired socialization, as well as decrease in academic skills. Objectives: The aim of this study was determine the negative impact of electronics use on Lebanese pediatric population aged between 2 and 6 years mainly involving sleep disturbances, change in general health status, increase aggressiveness and worsening of general manners. Methods: A descriptive cross sectional questionnaire was distributed over 966 families of Lebanese children aged between 2 and 6 years, in different Lebanese countries including some Lebanese schools, and collected. Demographic data included: age of child, type of electronic device used, whether parents depend on electronics to distract their children and calm them down, and to assess if parents know the amount of hours allowed for the child to spend on electronics. Data collected for the outcome included: number of hours spent on electronics, electronic use causing sleep disturbances in children, change in general health status, and increase aggressiveness and worsening in general manners. Results: During the study period, questionnaires were distributed over 966 families of Lebanese children aged between 2 and 6 years and collected. The mostly used electronic device in children was the IPAD (56.7\%) followed by smart phone $(50.1 \%)$. Our study showed that the more number of hours spent on electronics (> $4 \mathrm{hrs}$ ) was associated with sleep disturbances (mean score of 54.6) (p value < 0.05). The more the number of hours spent on electronics by the child, the decline in the general health status was noticed with a mean score of 41.5 when child used 4 hours or more and was statistically significant ( $p$ value $<0.05$ ). The more the number of hours spent on electronics, the more the child's manners worsens and decline is noticed in his social behavior with mean score of 41.7 at 4 hours of use (p value < 0.05). Conclusion: Electronics use is increasing dramatically among Lebanese children aged between 2 and 6 years. The more the number of hours spent on electronics was associated with sleep disturbances, decline in general health status, and worsening in social behavior and general manners.

Keywords: Electronic device; Children; social behavior.

Copyright @ 2020: This is an open-access article distributed under the terms of the Creative Commons Attribution license which permits unrestricted use, distribution, and reproduction in any medium for non-commercial use (NonCommercial, or CC-BY-NC) provided the original author and source are credited.

\section{INTRODUCTION}

Using electronics is among the most common activity of today's children and adolescents. During the past 5 years, the number of adolescents and preadolescents using such electronics has increased dramatically [1]. Although electronic devices help people communicate with each other, facilitates news feeds, entertains through many popular applications, one must not forget the crucial role of electronics in affecting behaviors, communicating skills, learning processes, and psychosocial behaviors. The negative impact of electronic devices excess use on youth is dramatically notable, well recognized effects are speech delay, decrease socialization, increase aggressiveness and lessens self-emotions towards others. This can be quiet frustrating as Rideout stated in 2010 that electronic devices misuse can affect mental health of teens and that their likelihood in getting depressed is increased, and that teens who tend to use mobile phone applications tend to be more narcissistic and aggressive [2].

Huesman stated that exposure to electronic media increase the risk of children and adults to behave aggressively [3]. Perkinon noted that excessive electronic media use at night is a risk factor for both adolescent sleep disturbance and depression [4]. Another study done by Mukaa in Kenya 2013 concluded that there were major behavioral problems observed among students due to electronic use. The major of these were sexual and violent behaviors [5]. 
Mingle stated that excess use of electronic devices can impact negatively on academic performance of youth if not used appropriately [6]. Based on the previous information, we found that assessing the negative impact of electronics on pediatric population is extremely important, as a way to increase awareness for limiting misuse of such facilities in one hand and to educate population about its negative impact on social behaviors, socialization skills, sleep disorders and aggressive behaviors.

\section{MATERIALS AND METHODS}

This was a descriptive cross sectional questionnaire, in which 966 questionnaires were distributed on families of Lebanese children aged between 2 and 6 years in different Lebanese regions including Bekaa, Beirut, North, and South and were collected. Most of these questionnaires where interview based in which the resident asked the parents the questions and fills the answers. Data was collected from February 2018 till February 2019. Demographic data included: Age of child, type of electronic device used, whether parents know how many hours are allowed for the child to spend on electronics, and whether parents usually tend to give the electronic device to calm the child down. Data collected for the outcome included the correlation between increased number of electronics used by child and decline in general health status, increase aggressiveness and change is social behavior, and increase sleep disturbances.

The first part of the questionnaire included 22 questions that analyzed the child's general health status whether declining in correlation with increased number of hours spent on electronics. Answers where labeled by $(0,1,2,3,4)$ and the total score was calculated respectively according to the item subscale. Subscales of general health status included: child's health evaluation, physical functioning, general health perception, physical role, change in health, general health and wellbeing.

The second part of the questionnaire analyzed the correlation between number of hours spent on electronics and increase aggressiveness in child and change in general manners. Subscales for general manners declined included; bodily pain, parental emotional impact, general manners, psychosocial and emotional impact, self-esteem, and the role social behavior. It included 22 questions also labeled by answers $(0,1,2,3,4)$ respectively. the total score was transferred to a mean score out of 100 , in which 0 labeled the worst possible state, and 100 resembled the best possible state. This is an international scoring system for the universal children health questionnaire, and we followed it to analyze our data.

The third part of questionnaire analyzed the correlation between the number of hours spent on electronics and sleep disturbances. It included multiple questions in which answers were labeled as $(0,1,2,3$, 4). The total score was also transformed to a mean score ranging from 0 to 100 , where 0 was the best and 100 was the worse.

\section{RESULTS}

During the study period, 1000 questionnaires were distributed and 966 were collected. The mostly used electronic device was the IPAD $(56 \%)$ followed by the smart phone $(50 \%)$ (Figure-1). $76 \%$ of parents depend on electronic device to calm their child down, whereas $24 \%$ didn't (Figure 2). Children of parents who use electronic devices to calm them down, were spending four hours or more on electronic devices (79\%) but with no statistical significance ( $\mathrm{p}$ value $=$ 0.49) (Figure-3).

However, when it comes to parent's knowledge about time allowed for their child to spend on smart devices, $61 \%$ did not know how much time is allowed, and $39 \%$ answered yes.

Smart devices use was highly correlated with sleep disturbances, where children who used $4 \mathrm{hrs}$ or more of electronic devices tended to have more sleep habits problems with a mean value of 54.6 with a statistically significant $(\mathrm{p}$ value $=0.035)($ Figure-4) .

It was also notable that children who spend more hours on electronic devices tended to have decline in their general health status with a mean value of 41.5 with a statistical significance $(\mathrm{p}$ value $=0.016)$ (Table1).

Moreover, yet dramatic, active child consumers of smart devices were suffering from decline in behavior and change in general manners, with increase in overall aggressiveness correlated to a mean value of 41.7 which was statistically significant ( $\mathrm{p}$ value $=0.001)$ (Table-2).

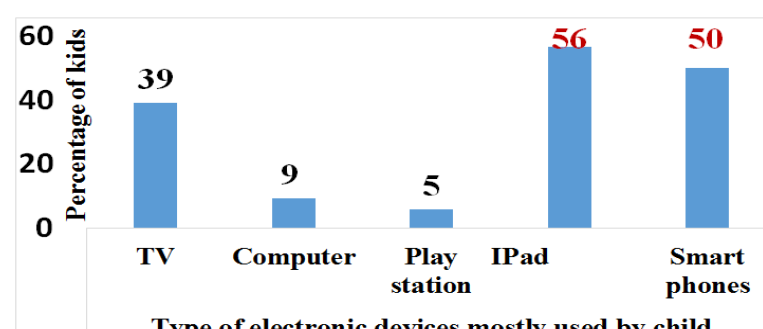

Type of electronic devices mostly used by child

Fig-1: Electronic devices used by children

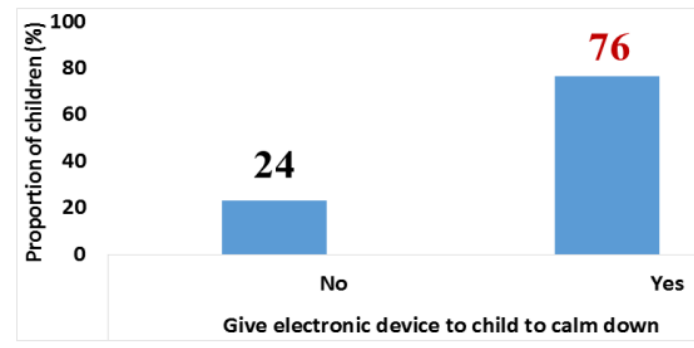

Fig-2: Parents dependence on electronics to calm child 


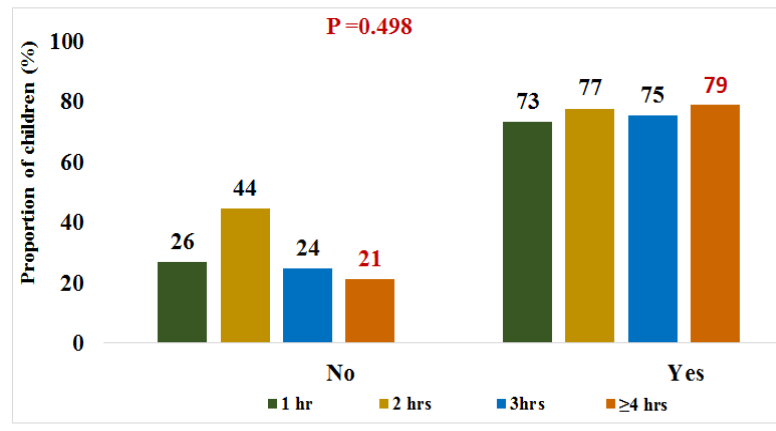

Fig-3: Correlation between Giving Device to Calm Child Down and Increase Number of Hours Spent

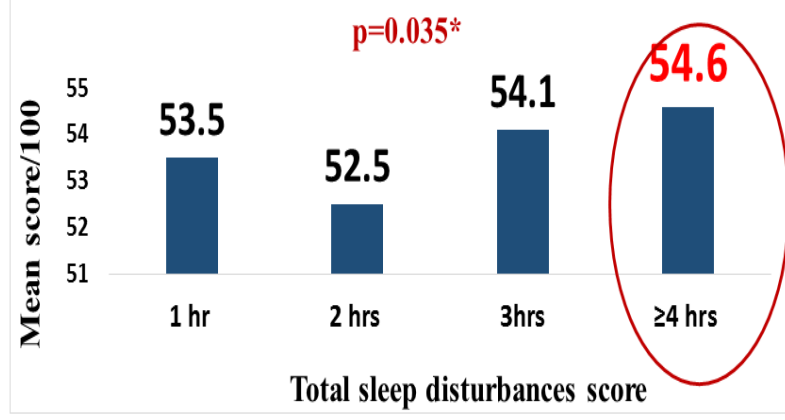

Fig-4: Correlation between Number of Hours Spent On Smart Devices and Sleep Disturbances

Table-1: Correlation between number of hours spent on electronics and general physical health status

\begin{tabular}{|c|c|c|c|c|c|c|}
\hline Item subscale & & $1 \mathrm{hr}$ & 2 hrs & $3 \mathrm{hrs}$ & $\geq 4$ hrs & P-value \\
\hline \multirow[t]{2}{*}{ Childs health evaluation } & Mean score/4 & $2.1(1.3)$ & $1.9(1.3)$ & $2(1.3)$ & $2.1(1.2)$ & 0.541 \\
\hline & Mean Score/100 & $52.2(31.6)$ & $49.7(31.7)$ & $50.5(32.6)$ & $53.4(30.9)$ & 0.541 \\
\hline \multirow[t]{2}{*}{ Physical functioning } & Mean score/24 & $12.5(4.5)$ & $12.1(3.9)$ & $12.1(3.6)$ & $12.3(3.4)$ & 0.659 \\
\hline & Mean Score/100 & $52.3(18.8)$ & $50.5) 16.3)$ & $50.6(14.9)$ & $51.4(14.2)$ & 0.659 \\
\hline \multirow[t]{2}{*}{ General health perception } & Mean score/12 & $6.7(2.3)$ & $6.7(2.3)$ & $6.5(2.3)$ & $6.9(2.2)$ & 0.143 \\
\hline & Mean Score/100 & $55.8(18.8)$ & $55.7(19.1)$ & $53.8(19.5)$ & $57.7(18.6)$ & 0.143 \\
\hline \multirow[t]{2}{*}{ Role social and physical } & Mean score/20 & $12.8(3.7)$ & $12.1(3.4)$ & $12.3(2.9)$ & $12.6(3.2)$ & 0.110 \\
\hline & Mean Score/100 & $64.2(18.4)$ & $60.6(17.1)$ & $61.2(14.8)$ & $62.8(15.8)$ & 0.110 \\
\hline \multirow[t]{2}{*}{ Change in health } & Mean score/12 & $5.6(2.2)$ & $5.5(2.2)$ & $5.8(1.9)$ & $5.9(2)$ & 0.057 \\
\hline & Mean Score/100 & $46.5(18.3)$ & $45.7(18.1)$ & $48.5(16.4)$ & $49.3(16.8)$ & 0.057 \\
\hline \multirow[t]{2}{*}{ Mental health and well being } & Mean score/16 & $9.8(3.3)$ & $9.7(2.7)$ & $9.4(2.2)$ & $9.6(2.8)$ & 0.562 \\
\hline & Mean Score/100 & $61(20.4)$ & $60.9(17)$ & $58.9(13.9)$ & $60.2(17.5)$ & 0.562 \\
\hline \multirow[t]{2}{*}{ Total physical health score (total of all above) } & Mean score/88 & $49.5(7.3)$ & $48.1(6.9)$ & $48.1(6.2)$ & $49.5(5.8)$ & 0.014 \\
\hline & Mean Score/100 & $56.8(8.3)$ & $54.7(7.8)$ & $54.7(7.1)$ & $56.4(6.6)$ & 0.014 \\
\hline
\end{tabular}

Table-2: Correlation between number of hours spent on electronics and child's manners and social behavior

\begin{tabular}{|c|c|c|c|c|c|c|}
\hline Number of hrs & & $1 \mathrm{hr}$ & 2 hrs & 3hrs & $\geq 4 \mathrm{hrs}$ & P-value \\
\hline \multirow{2}{*}{ Bodily pain } & Mean score/8 & $5.2(1.9)$ & $5.2(1.8)$ & $5.6(1.9)$ & $5.6(1.7)$ & 0.002 \\
\hline & Mean Score/100 & $65.2) 23.6)$ & $64.6(22.8)$ & $70.4(23.6)$ & $70.4(20.9)$ & 0.002 \\
\hline \multirow[t]{2}{*}{ Parental emotional impact } & Mean score/16 & $9.1(3)$ & $8.8(2.9)$ & $9.4(3.1)$ & $9.6(2.8)$ & 0.004 \\
\hline & Mean Score/100 & $57(19)$ & $54.8(18.2)$ & $58.4(19.1)$ & $60.2(17.5)$ & 0.004 \\
\hline \multirow[t]{2}{*}{ General manners } & Mean score/5 & $2.4(1.5)$ & $2.6(1.4)$ & $2.7(1.5)$ & $2.4(1.5)$ & 0.030 \\
\hline & Mean Score/100 & $47.1(29.3)$ & $52.3(27.9)$ & $54.7(29.2)$ & $48.7(29.8)$ & 0.030 \\
\hline \multirow{2}{*}{$\begin{array}{l}\text { Psychosocial emotional factor } \\
\text { and manners }\end{array}$} & Mean score/20 & $11.3(3.4)$ & $11.5(3.3)$ & $11.4(3)$ & $11.1(3.1)$ & 0.581 \\
\hline & Mean Score/100 & $56.6(16.9)$ & $57.3(16.5)$ & $57.1(15.1)$ & $55.6(15.4)$ & 0.581 \\
\hline \multirow[t]{2}{*}{ Self esteem } & Mean score/16 & $9.4(3.1)$ & $9.2(2.9)$ & $9.5(2.3)$ & $9.4(2.5)$ & 0.511 \\
\hline & Mean Score/100 & $59(19.5)$ & $57.5(18)$ & $59.6(14.4)$ & $58.5(15.9)$ & 0.511 \\
\hline \multirow[t]{2}{*}{ Role social behavioral } & Mean score/20 & $11.7(2.8)$ & $11.7(2.8)$ & $12.3(2.7)$ & $11.6(2.6)$ & 0.015 \\
\hline & Mean Score/100 & $58.3(14.3)$ & $58.7(13.9)$ & $61.6(13.6)$ & $58(13.01)$ & 0.015 \\
\hline \multirow{2}{*}{$\begin{array}{l}\text { Total child's manners and social } \\
\text { behavior (Total of the above) }\end{array}$} & Mean score/85 & $49.1(6.8)$ & $48.9(6.4)$ & $51(6.1)$ & $49.8(6.1)$ & 0.001 \\
\hline & Mean Score/100 & $57.8(8)$ & $57.6(7.5)$ & $60(7.1)$ & $58.6(7.2)$ & 0.001 \\
\hline
\end{tabular}

\section{DISCUSSION}

To the best of our knowledge, our study is the first study done in Lebanon analyzing the negative impact on the Lebanese pediatric population. Dramatically, $100 \%$ of the children enrolled in this study are active consumers of smart devices.

Our study showed that pediatrics who consume more hours on electronic devices were more aggressive, and had decline in their general behaviors. these results were similar to those reported by Huessman et al., in 2007, who stated that children who use such devices are more prone to be violent. Children in the united states tend to spend around $4 \mathrm{hrs}$ on television daily and around $60 \%$ of the programs shown on TV contained some violence and about $40 \%$ were nothing but violence. Exposing a kid to a violent behavior will produce nothing but aggressiveness and bad manners [4]. 
Moreover, our study showed that electronic use was associated with sleep disturbances in children. Results were similar to those of Neralie Cain et al., who stated that screen time was associated with delayed bed time in school aged children, and that it impacted negatively their sleep over all. Shorter total sleep time was also linked to electronic devices use, as well as wakening up at night and it also affected sleep quality and childs physical activity [7].

Our study showed that smart devices use in children was associated with psychosocial disturbances and decline in general health status. Jade McNeill et al., stated the same in 2019 in which he discussed how electronics tend to cause psychological problems, cognitive delay.

He claimed that limiting electronic use to less than 30 minutes per day in pediatric population lead to cognitive improvement and limited somehow psychosocial problems in preschoolers [8].

It is well known that today's children are very immersed in smart media, and parents have an important role in limiting over use of such devices. It is known to cause delay in physical activity, and to decrease socialization. The American academy of pediatrics recommends for children less than 18 months to completely be banned from electronic devices, and to limit it in children aged from 2 to 5 years to one hour per day. For children aged more than 6 years, AAP recommends that smart media must be limited, and to make sure it does not take part of the physical activity, face to face interactions, socialization, and general behavior. On the other hand, parents and physicians play an important role in limited misuse of such electronics and limiting time of use of such devices [9].

There was truly an empirical lack in studying the negative impact of smart media on pediatrics. Since electronic media has become more accessible, the prevalence of use of such devices is increasing dramatically among children. It is well noted that the use of TV is declining, and smart media is replacing it. In Korea for example $98 \%$ of population owned smart devices. This is quiet frustrating since it has become in the hands of their children. It has shown that electronic media lead to increase percentage of obesity and attention deficit. On the other hand, sleep habits are influences by them, and causes over all delay. Probably because of sounds and attractive lights, children are more prone to use those devices and maybe become addictive [10]. It is frustrating of how these devices are substituting child's physical activity and social communication.

\section{CONCLUSION}

Electronic devices use is increasing dramatically among Lebanese pediatric population. Excessive use of these devices is correlated with sleep disturbances, increase aggressiveness, and change in general health status among these children. Most Lebanese families find it an easy way to distract the child and calm him down, unaware of frustrating consequences on child's general wellbeing. It is very crucial to initiate programs that increase awareness toward the negative impact of electronic devices on Lebanese children. Further studies are to be done including larger sample sized and studying further consequences of smart devices use.

\section{REFERENCES}

1. O'Keeffe GS, Clarke-Pearson K. Council on communications and media. The impact of social media on children, adolescents, and families. Pediatrics. 2011 Mar;127(4):800-4.

2. Rideout VJ, Foehr UG, Roberts DF. Generation M2: Media in the lives of 8-18year olds. 2010. Retrieved on May 15, 2011 from Kaiser Family Foundation http://www.kff.org/entmedia/upload/8010.pdf

3. Rosen LD. Social networkings good and bad impact on kids, August 2011.

4. Huesmann LR. The impact of electronic media violence: Scientific theory and research. Journal of Adolescent health. 2007 Dec 1;41(6):S6-13.

5. Rosempta N. John Influence of Electronic Media on Behavior Among Secondary School Students In Mukaa District, Makueni County, Kenya, The Catholic University of Eastern Africa Kenya, 2013

6. Jeffrey M, Musah A. Social Media Network Participation and Academic Performance in Senior High Schools in Ghana, 2015, library philosophy and Practice (e-journal). 1286. JAMA Pediatr. 2014;168(5):485-492.

7. Cain N, Gradisar M. Electronic media use and sleep in school-aged children and adolescents: A review. Sleep medicine. 2010 Sep 1;11(8):735-42.

8. McNeill J, Howard SJ, Vella SA, Cliff DP. Longitudinal Associations of Electronic Application Use and Media Program Viewing with Cognitive and Psychosocial Development in Preschoolers. Academic pediatrics. 2019 Mar 8.

9. AAP, Recommendation for Children Media Use, Oct 212016.

10. Chang HY. Electronic Media Use And Exposure Among Toddlers, Psychiatry investigation, May 242018. 